\title{
A Structural Design of COVID-19 Patient Lifting Device Using Crane and Hydraulic Mechanism
}

\author{
D.C. Hardiyasanti ${ }^{1,2}$, S. Widianingrum ${ }^{1,2}$, F. Bestiara ${ }^{1,2}$, M. Syaroh ${ }^{1,2}$ and F. Triawan ${ }^{1, *}$ \\ 1Department of Mechanical Engineering, Faculty of Engineering and Technology, \\ Sampoerna University, Jakarta, Indonesia \\ 2Department of Aerospace and Mechanical Engineering, The University of Arizona, Tucson, AZ, 85721, USA. \\ *E-mail: farid.triawan@sampoernauniversity.ac.id
}

\begin{abstract}
COVID-19 has brought the mankind into the worst condition. The health care workers as the forefront player during this pandemic are psychology and physically exhausted. In 2021, the infected patient is decreasing in some countries, yet increasing in others. Therefore, this study is aimed to design and analyze a patient lifting device in order to help the health workers in handling paralyzed and bone traumatic patients in effective way. This lifting device is designed to be operated by only one person and contactless with the patient. Thus, the healthcare worker can work on safety procedure of COVID-19. The structural design of the device is using the concept of crane and hydraulic mechanism that can handle a maximum weight of 2,000 N. Every mechanical part that is considered critical becomes the focus in the strength analysis. The analysis is done by theoretical approach under static and dynamic loading. As the results, the static and fatigue analyses show that the most critical part of the lifting device is at the fork structure with safety factor of 1.04. This indicates the design is in safety condition and could have an infinite service life cycle.
\end{abstract}

Keywords : Lifting device, COVID-19 patient, Structural design, Strength analysis, Static and Fatigue.

\section{INTRODUCTION}

In Indonesian medical sectors, there are several technologies that have not been distributed evenly in all hospitals (Misnaniarti et al., 2018). It is proven by 4 classifications of hospital in term of service, human resources, medical equipment, and management (Oktamianti \& Pebrina, 2019). The need of a mechanism which can ease the task of medical personnel is significantly needed even more during the spread of COVID-19. This virus has increases Indonesian crisis related with economy, communication and inevitably healthcare (Muryanti et al., 2021). However, the demand of healthcare itself is irrelevant with the number of the servicers which result in more health issue of the healthcare workers (HCW). Therefore, they are facing burnout or psychological response related to chronic stress while interacting with the patient (Rusca Putra \& Setyowati, 2019), and undeniably they are also physically over exhausted during the pandemic. Moreover, dramatically, there are over 100 doctors and hundreds of healthcare workers (HCW) has been died reported in Indonesia on September 2020, and according to scientific research within the first 6 months of the virus spread, 51,7\% of HCW was positive corona virus (Gholami et al., 2021). 
Establishing a safe and effective flow of patient care remains essential and must be practiced at all levels of hospitals. Medical personnel who are at the forefront of handling the COVID-19 virus pandemic have been alerted and continue to carry out these duties in various hospitals. Even the vaccines have been distributed, similar novelty virus might occur in the future such as the heartbreaking pandemic situation in India which reported in World Health Organization (WHO) on 26 April 2021 (Pal \& Yadav, 2021). Thus, the readiness to face any pandemic should be prepared.

One of the health issues which encountered by HCW is due to activity such us lifting heavy weight and transferring paralyzed and bone traumatic patient; these factors were studied by proportional random sampling of $73 \mathrm{HCW}$ to be the factor of low back pain of nurses (Aljohani \& Pascua, 2019; Boughattas et al., 2017). Moreover, commonly the number of people involved in lifting, lowering, and transferring patient is 3-4 workers, which during the spread of COVID-19 these number should be reduced for effectiveness and less physically contact between the patient and the HCW as the action to reduce the number of COVID-19 infection in hospital (Khoiriyah et al., 2021).

The existing of similar device has been manufactured by several brands such as Barton and Hoyerlift (Pookarath \& Parameswaran, 2018). The three of them are using the same crane design, and the hydraulic system is used as the additional buffer to lift and lower the arm which is functioned to hang up the patient. Moreover, there are no published papers and journals about the development and structural design of a patient lifting device found in the online database.

Therefore, the objective of this paper is designing an innovative patient lifting device which can alleviate the Indonesian HCW as the front barrier of COVID-19 pandemic to lift, lower, and transfer patient which can be operated by only 1 person and can withstand up to 2,000 $\mathrm{N}$ of load. In addition, this study is aimed to be useful for the development of healthcare technology, especially in Indonesia. This paper is also provided with the strength analysis under statics and dynamics loading for the feasibility and the service life prediction.

\section{METHODOLOGY}

The development of patient lifting device meets some boundaries to focus with the designated purpose. The limitation specifically focuses on its dimension which has roughly 500 $\times 1,500 \times 2,000 \mathrm{~mm}$, can be operated by only 1 person, and can withstand 2,000 $\mathrm{N}$ of load. Therefore, a guidance on engineering design by Budynas et al. and Oktaviandri et al. on Figure 1 is adopted. The flow is iterative; thus, it is suitable to have a significant optimization before it is presented to the public. The significant optimization can be achieved right after the design and its strength analysis is done. In this case, since the device will be handled by one person, therefore simple design becomes the goal, and if the initial calculation does not satisfy the infinite life cycle on dynamic loading, the material or geometry need to be changed until it meets the requirement. 


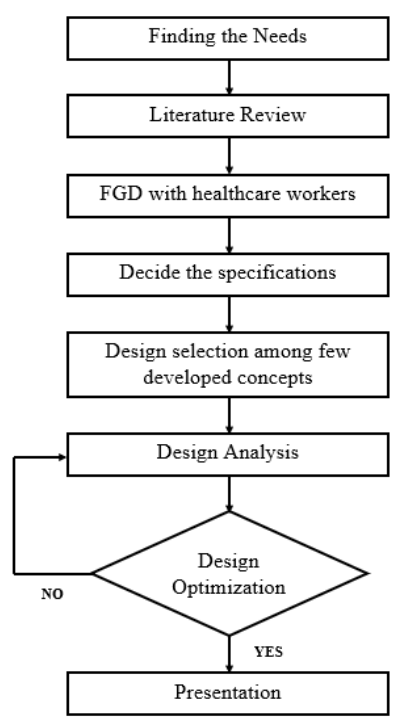

Figure 1. Design Process (Budynas et al., 2020; Oktaviandri \& Paramasivam, 2020)

\subsection{Design Concept}

By conducting Focus Group Discussion (FGD) of $10 \mathrm{HCW}$ who work in diverse hospital in Java Island, Indonesia on March 2021, it is found that all of them has experienced lifting patients. $70 \%$ of the respondent state that the process was done manually without any help of any device nor machine, $20 \%$ of respondents have equipped with patient lifting device yet still insufficient, for the device is only available in certain room such as Emergency Room (ER). This imply that the need of mechanism which can help in this task is needed. Moreover, from the FGD, it is known also that the number of HCW involved in patient lifting is from 34 people. Therefore, the mechanism should be operated by less people, especially during the pandemic.

The design concept is inspired by a crane and hydraulic mechanism which can lift, lower, and transport object. The lifting and lowering mechanism are using the hydraulic jack pump as stated in Figure 2. The user can easily adjust the height of the device even when the loading is bigger than his/her power by repeatedly pulling the lever arm until the desired height is reached. To see the entire design in isometric view with its main components, the device can be seen in Figure 3.

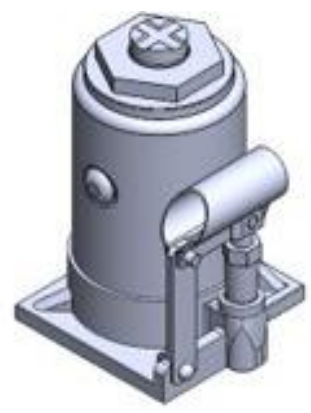

Figure 2. Hydraulic Pump 


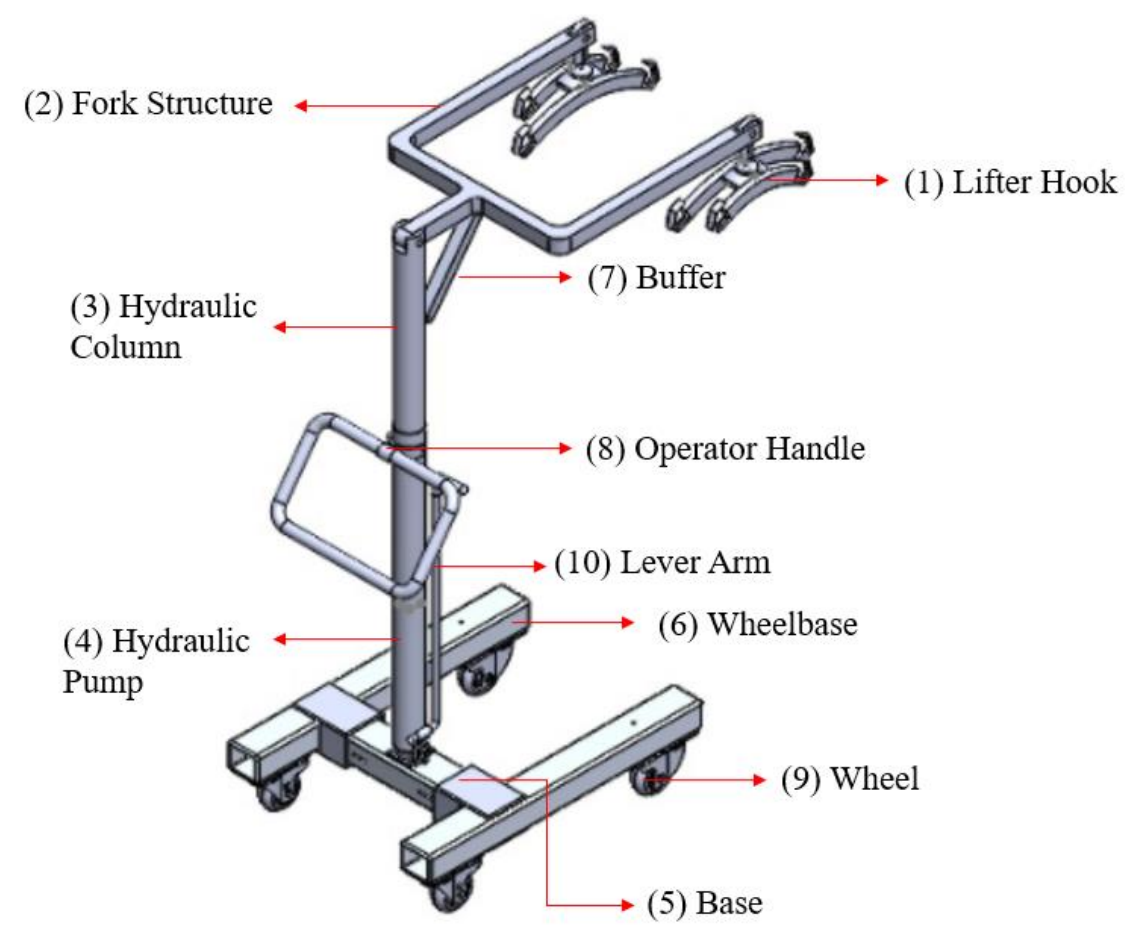

Figure 3. Isometric View with the Components' names

To get to know more about the design, the list below is made to explain each part and its mechanism refer to Figure 3.

1. The (1) Lifter Hook structure is to hook the patient lifter, it can be rotated $360^{\circ}$ and connected to various types of carrier devices depending on the user's condition.

2. The (2) Fork Structure is made with intention to give stable position as the patient is lifted, and it is connected with a rectangular beam as the supportive component to increase the strength of the structure.

3. The (3) Hydraulic Column made of a hollow cylinder and the height can be adjusted along $0.7 \mathrm{~m}$. This column is the extension of the hydraulic mechanism which can be heighten and lowered.

4. The (4) Hydraulic Pump located inside the hollow cylinder to push up and down the hydraulic column in order to adjust the height of the device in use.

5. The (5) Base is used to connect the two (6) Wheelbases of the mechanism, so that it can be stable. Then the wheelbase is connected to the wheels so that the device can be carried and moved easily, even when the patient is on the device.

6. The (7) Buffer is created to minimize the bending of the fork structure, and the (8) Operator Handle is used to move the mechanism or give additional balancing to the system.

7. The (9) Wheels are consisting of 4 that has stoppable and can be rotated $360^{\circ}$ features.

8. The (10) Lever Arm is the part where the operator will handle the mechanism. It is located at the end of hydraulic pump. The height will be stuck on the last pump of the lever arm, and it will be lowered when the valve is open to release the air pressure on the hydraulic. 
With those specifications, Figure 4 provided the system from three views. Figure 4(a), (b), and (c) are showing the mechanism from front, side, and upper view.

\subsection{Material Selection}

The material for the patient lifting device should be strong to hold the mass of an adult. The weight of the system also should not be heavy because it designed to be operated by 1 person. Based on those requirements, high carbon steel is considered because this material has more specific advantages such as: a) safety for human use, b) less ductile, c) resistance to wear, d) extreme hardness, and e) weldable compared the other ordinary steel material (Gorkunov et al., 2017).

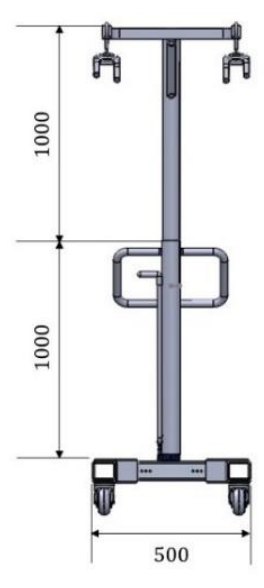

(a)

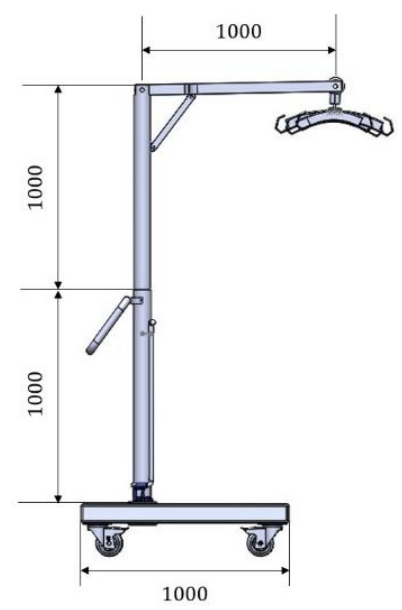

(b)

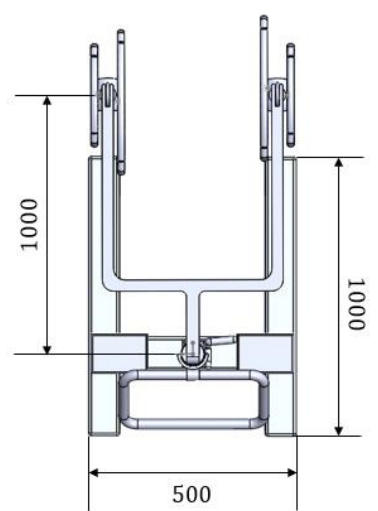

(c)

Figure 4. (a) front view, (b) side view, and (c) top view of the system in $\mathrm{mm}$

To be specific, the used material is Cold-Drawn High Carbon Steel AISI 1080 (Saptaji et al., 2019). This material has density of $7.8 \mathrm{~g} / \mathrm{cm}^{2}$, and high melting point about 1289-1478 ${ }^{\circ} \mathrm{C}$. With the maximum service temperature near the room temperature, Cold-Drawn High Carbon Steel AISI 1080 has the value of tensile strength of $780 \mathrm{MPa}$ and the yield strength of $590 \mathrm{MPa}$ (Badaruddin et al., 2020). With those specifications, the material could fulfil the needs for the system to work properly with safety factor in static analysis and fatigue analysis at least $>1$ (Zulaikah et al., 2020).

\subsection{Component Design}

The design is created using SOLIDWORKS software application. There are three types of beam shapes that are used to construct the whole system design. They are rectangular solid, rectangular hollow, and cylindrical hollow. The use of hollow is to reduce the weight as well as the cost.

The dimension used in this design has been verified by conducting some research in order to know the availability in the marketplace. Table 1 provide the information about the dimension and beam type which significantly affect the strength calculation. 
Table 1 Beam's dimension and type

\begin{tabular}{|l|l|l|}
\hline Components & Dimension $[\mathrm{mm}]$ & Beam type \\
\hline 1 & $\mathrm{~W}^{*}=25.4 ; \mathrm{H}=20 ; \mathrm{L}=300$ & Rectangular solid \\
\hline 2 & $\mathrm{~W}=50 ; \mathrm{H}=40 ; \mathrm{L}=1000$ & Rectangular solid \\
\hline 3 & $\mathrm{D}_{\mathrm{o}}=56 ; \mathrm{D}_{\mathrm{i}}=36 ; \mathrm{L}=1000$ & Cylindrical hollow \\
\hline 4 & $\mathrm{D}_{\mathrm{o}}=85 ; \mathrm{D}_{\mathrm{i}}=61 ; \mathrm{L}=1000$ & Cylindrical hollow \\
\hline 5 & $\mathrm{~W}=100 ; \mathrm{H}=50 ; \mathrm{T}=4 ; \mathrm{L}=500$ & Rectangular hollow \\
\hline 6 & $\mathrm{~W}=70 ; \mathrm{H}=50 ; \mathrm{T}=4 ; \mathrm{L}=1000$ & Rectangular hollow \\
\hline 7 & $\mathrm{~W}=30 ; \mathrm{H}=40 ; \mathrm{L}=424$ & Rectangular solid \\
\hline
\end{tabular}

*Where $W$ is weight; $H$ is height; and $L$ is length.

\subsection{Static Analysis}

Static analysis is conducted to calculate the properties of the system based on the system's dimensions and the force that given to the system in the static condition which affected each of the components. The final aim in static analysis is the static safety factor of each components. After the data from Free Body Diagram (FBD) static equilibrium analysis already gather up, use the equations as following to conduct the theoretical analysis.

$$
\begin{aligned}
& \sigma=\frac{M c}{I} \\
& I=\frac{1}{12} b d^{3} \text { or } I=\frac{\pi}{64}\left(d o^{4}-d i^{4}\right) \\
& \sigma_{\max }=K_{t} \sigma_{a v g} \\
& \tau=\frac{3}{2} \frac{V}{A} \quad \text { or } \tau=\frac{V Q}{I t} \\
& n_{s}=\frac{S_{y}}{\sigma^{\prime}}
\end{aligned}
$$

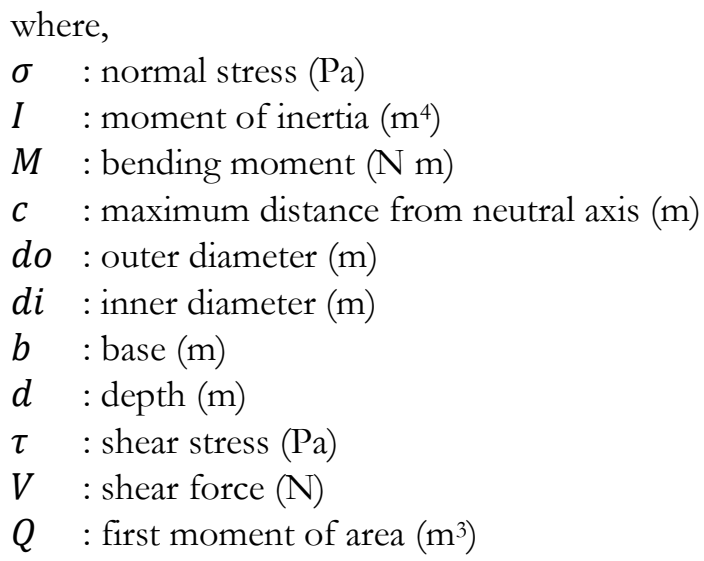




$$
\begin{array}{ll}
A & : \text { area }(\mathrm{m}) \\
n & : \text { safety factor } \\
S_{y} & : \text { yield strength }(\mathrm{Pa})
\end{array}
$$

\subsection{Fatigue Analysis}

The fatigue analysis is performed to determine the service life and fatigue safety factor of the proposed product (Budiman et al., 2020; Iswanto, 2020). However, the component that will be analyzed is only the component that will experience the fluctuated loading (dynamic loading). Below are the equations for finding the Marin factors.

$$
\begin{aligned}
& S_{e}=k_{a} k_{b} k_{c} k_{d} k_{e} k_{f} S_{e}^{\prime} \\
& k_{a}=a S_{u t}^{b}
\end{aligned}
$$

$$
k_{b}=\left\{\begin{array}{lc}
0.879 d^{-0.107} & 0.11 \leq d \leq 2 \mathrm{in} \\
0.91 d^{-0.157} & 2<d \leq 10 \mathrm{in} \\
1.24 d^{-1.107} & 2.79 \leq d \leq 51 \mathrm{~mm} \\
1.51 d^{-0.157} & 51<d \leq 254 \mathrm{~mm}
\end{array}\right.
$$

For axial loading, $k_{b}=1$

For non-rotating or hollow round, $d_{e}=0.307 d$

For rectangular section of dimension, $d_{e}=0.808(h b)^{\frac{1}{2}}$

$k_{c}=\left\{\begin{array}{cc}1 & \text { bending } \\ 0.85 & \text { axial } \\ 0.59 & \text { torsion }\end{array}\right.$

$S_{e}{ }^{\prime}=\left\{\begin{array}{cc}0.5 S_{u t} & S_{u t} \leq 200 \mathrm{kpsi}(1400 \mathrm{MPa}) \\ 100 \mathrm{kpsi} & S_{u t}>200 \mathrm{kpsi} \\ 700 \mathrm{MPa} & S_{u t}>1400 \mathrm{MPa}\end{array}\right.$

where,

$S_{e} \quad$ : endurance strength

$S_{e}^{\prime}:$ ideal endurance strength

$S_{u t}$ : ultimate tensile strength

$k_{a}$ : surface condition modification factor

$k_{b}$ : temperature modification factor

$k_{c}:$ load modification factor

$k_{d}$ : temperature modification factor

$k_{e}:$ reliability factor

$k_{f}$ : miscellaneous-effects modification factor 
If the component has stress-concentrated factor, $K_{t}$, it means that the component also has fatigue stress-concentrated factor, $K_{f}$. The fatigue-concentrated factor needs to be calculated because it can magnify stress value. For that, this formula can be used to calculate the fatigue-concentrated factor.

$$
K_{f}=1+\frac{K_{t}-1}{1+\sqrt{a / r}}
$$

For bending, $\sqrt{a}=0.246-3.08\left(10^{-3}\right) S_{u t}+1.51\left(10^{-5}\right) S_{u t}^{2}-2.67\left(10^{-8}\right) S_{u t}^{3}$

$$
\begin{aligned}
& \text { where, } \\
& K_{f} \quad: \text { fatigue-concentrated factor } \\
& K_{t} \quad: \text { stress-concentrated factor } \\
& a \quad: \text { modification factor } a \\
& r \quad: \text { radius of the notch }
\end{aligned}
$$

Then, here are the equations for finding the $\sigma_{a}, \sigma_{m}$, and $\sigma_{r e v}$.

$$
\begin{gathered}
\sigma_{r e v}=\frac{\sigma_{a}}{1-\frac{\sigma_{m}}{S_{u t}}} \\
\sigma_{a}=\left|\frac{\sigma_{\text {max }}-\sigma_{\text {min }}}{2}\right| \\
\sigma_{m}=\frac{\sigma_{\text {min }}+\sigma_{\text {max }}}{2}
\end{gathered}
$$

where,

$\sigma_{\text {rev }}:$ reversed stress

$\sigma_{a}:$ amplitude component

$\sigma_{m}:$ midrange component

$\sigma_{\min } \quad:$ minimum stress

$\sigma_{\max } \quad:$ maximum stress

From all those calculations, now the fatigue safety factor can be determined.

$$
\begin{aligned}
n_{f}= & \frac{s e}{\sigma_{r e v}} \quad \text { or } \quad n_{f}=\frac{s e}{\sigma_{r e v} K_{f}} \\
\text { where, } n_{f} & : \text { fatigue safety factor }
\end{aligned}
$$

\section{RESULT AND DISCUSSION}

In the strength analysis, static analysis and fatigue analysis are carried out in the whole system. From these analysis and calculation, the most critical part or component of the entire system can be obtained. According to the design specification, it is set that the load is 2,000 N. Hence, the FBD of the whole system is shown in the Figure 5. By considering the device as a whole, the value of the reaction forces on each wheel can be determined easily. Moreover, the 
value of 2,000 $\mathrm{N}$ comes from the maximum load that this mechanism must achieve for the secondary specification. From the FBD of whole system, the maximum shear force and bending moment can be analysed by break it down into each component internal force. By using the statics equilibrium formula, the maximum shear force and bending moment can be seen through Shear Force Diagram (SFD) and Bending Moment Diagram (BMD) in Figure 7.

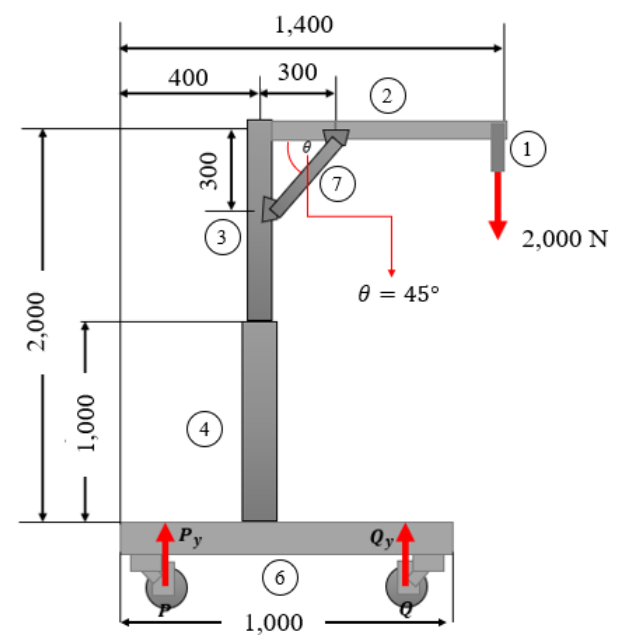

Figure 5. Free Body Diagram of Patient Lifting Device (all dimension in millimeter)

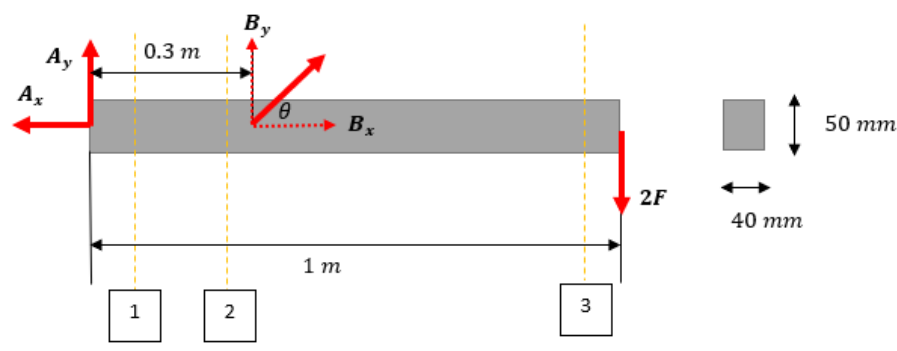

Figure 6. Internal Force at Component 2 


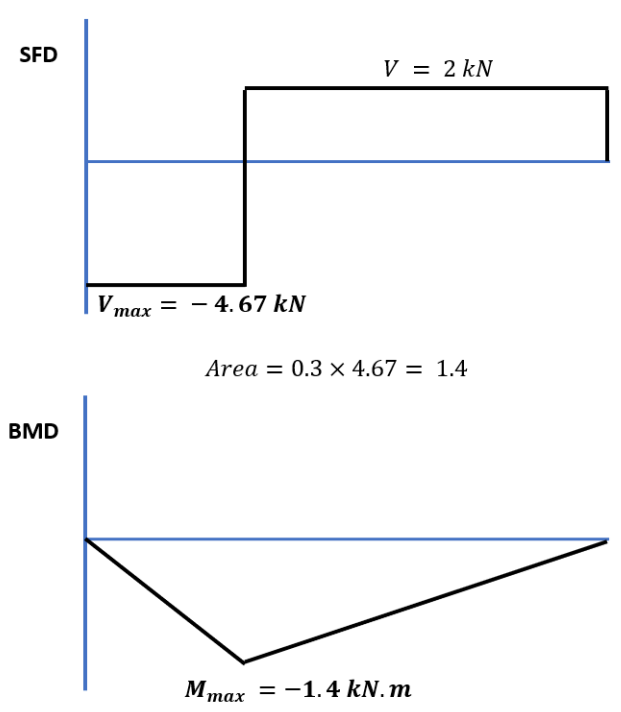

Figure 7. SFD and BMD of Component 2

Figure 6 shows the free body diagram of internal force in component 2 which loaded by 2,000 $\mathrm{N}$ loading. Then, from the static equilibrium formula, the value of maximum shear force for component 2 is $4.67 \mathrm{kN}$, while for the maximum bending moment is $1.4 \mathrm{kN} . \mathrm{m}$. Moreover, these value for all components can be seen in Table 2. It is known that the critical shear force and bending moment is located on component 2 and 3.

Table 2. List of Maximum Shear Force (V), Bending Moment (M), and Axial Force (P)

\begin{tabular}{|c|c|c|c|}
\hline Components & $\boldsymbol{V}_{\boldsymbol{m a x}}(\boldsymbol{k N})$ & $\boldsymbol{M}_{\boldsymbol{m a x}}(\boldsymbol{k N} \boldsymbol{N} \boldsymbol{m})$ & $\boldsymbol{P}(\boldsymbol{k N})$ \\
\hline 1 & 0.5 & 0.075 & - \\
\hline 2 & 4.67 & 1.4 & - \\
\hline 3 & 4.67 & 1.4 & - \\
\hline 4 & 2.0 & 2 & - \\
\hline 5 & 1.0 & 0.25 & - \\
\hline 6 & 1.4 & 0.84 & - \\
\hline 7 & - & - & 9.43 \\
\hline
\end{tabular}

\subsection{Strength under Static Loading}

The stress analysis is conducted to find the safety factor of each component of the system. By using the values in Table 2, the stress analysis of all components can be calculated. Based on the calculations, it was obtained that the most critical component is component 2, which indicated by the smallest value of safety factor than the other components. Therefore, it will be discussed and calculated in detail as the following explanation.

To obtain the value of normal and shear stresses, it needs information such as the area and the moment of inertia. In Table 3 shows the area and moment of inertia of all components. The maximum normal stresses of each component can be calculated using the Equation (1). From the calculation, the maximum bending moment and maximum shear force is located at 
component 2 and 3. Below is the detail of calculation how to find the maximum normal stress at component 2 .

$$
\sigma_{\max }=\frac{M c}{I}=\frac{(1400000 \mathrm{~N} \cdot \mathrm{mm})\left(\frac{50}{2} \mathrm{~mm}\right)}{4.167 \times 10^{5} \mathrm{~mm}^{4}}=83.993 \mathrm{MPa}
$$

The stress concentration on components 1 and 2 exist due to the hole to attach the sling and lifter hook, respectively. The normal stress multiplies with stress concentration factor $K_{t}$ is obtained by Equation (3). Therefore, the values of maximum normal stress of component 1 and 2 is changing due to the stress concentration factor. Then, the values of maximum normal stresses of all components are listed in Table 3. Hence, the calculation for the maximum normal stress due to stress concentration in component 2 as follows.

$$
\begin{gathered}
\sigma_{\max }=K_{t} \sigma_{a v g} \\
\sigma_{\max }=K_{t}\left(\frac{M c}{I}\right)
\end{gathered}
$$

Where $I=(w-d) \frac{h^{3}}{12}$

$$
\frac{d}{h}=0.125 ; \frac{d}{w}=0.1
$$

Thus, from Figure A-15-2 (Budynas, 2020), $K_{t}=2.6$

$$
\sigma_{\max }=2.6\left(\frac{700000 \mathrm{~N} \cdot \mathrm{mm}\left(\frac{50}{2} \mathrm{~mm}\right)}{(50-5) \frac{40^{3}}{12} \mathrm{~mm}^{4}}\right)=189.58 \mathrm{MPa}
$$

Then, for the shear stress of each component can be calculated using Equation (4). Table 3 shows the value of shear stress of all components. Below is the detail calculation for shear stress of component 2 . Because the bar is solid rectangular, the formula is in the following.

$$
\tau=\frac{3}{2} \frac{\mathrm{V}}{\mathrm{A}}=\frac{3}{2}\left(\frac{4670 \mathrm{~N}}{2 \times 10^{-3} \mathrm{~m}^{2}}\right)=3502500 \mathrm{~Pa}=3.503 \mathrm{MPa}
$$

After obtaining the value of maximum normal and shear stresses, it is shown that $\sigma_{\max }>\tau_{\max }$. Thus, it is considered that stress and fatigue at the surface element is due to bending. Since it is assumed as a plane stress, $\sigma_{x}=\sigma_{\max }$ while $\sigma_{y}=\tau_{x y}=0$. Thus, by using the Distortion Energy (DE) criterion, the Von Mises stress is $\sigma^{\prime}=\sigma_{x}$. In Table 3 can be seen the Von Mises stress for all components.

From the Von Mises stresses' value, the safety factor can be calculated by using Equation (5). This equation is used the DE criterion for ductile material. Here, the materials used in this design is carbon steel AISI 1080, which has the value of yield strength $S_{y}$ is $590 \mathrm{MPa}$. The component 2 is the most critical part in this design. Therefore, the safety factors are obtained using the calculation below.

$$
n_{s}=\frac{S_{y}}{\sigma^{\prime}}=\frac{590}{189.58}=3.11
$$

Table 3 shows the safety factor of all components. The most critical component is component 2, which has 3.11 value of safety factor. Since this value is bigger than 1 , component 2 is still in the safety zone. In addition, this indicates that the material of the design has been considered properly, so that there is no risk of failure when it is given a maximum load of 2,000 N. 
D.C. Hardiyasanti et al. / Journal of Mechanical Design and Testing 3(2), (2021), 133-147

Table 3. Stress Analysis Result

\begin{tabular}{|c|c|c|c|c|c|c|}
\hline \multirow{2}{*}{ Components } & Area $\left(\mathrm{m}^{\mathbf{2}}\right)$ & $\begin{array}{c}\text { Moment of } \\
\text { Inertia } \mathbf{( m}^{4} \text { ) }\end{array}$ & $\begin{array}{c}\text { Maximum } \\
\text { Normal } \\
\text { Stress } \\
\mathbf{( M P a )}\end{array}$ & $\begin{array}{c}\text { Maximum } \\
\text { Shear Stress } \\
(\mathbf{M P a})\end{array}$ & $\begin{array}{c}\text { Von } \\
\text { Mises } \\
\text { Stress } \\
(\mathbf{M P a})\end{array}$ & $\begin{array}{c}\text { Statics } \\
\text { Safety } \\
\text { Factor, } \\
\boldsymbol{n}_{\boldsymbol{s}}\end{array}$ \\
\hline $\mathbf{1}$ & $5.08 \times 10^{-4}$ & $2.73 \times 10^{-8}$ & 160.18 & 1.476 & 160.18 & 3.68 \\
\hline $\mathbf{2}$ & $2 \times 10^{-3}$ & $4.167 \times 10^{-7}$ & 189.58 & 3.503 & 189.58 & 3.11 \\
\hline $\mathbf{3}$ & $1.45 \times 10^{-3}$ & $4.003 \times 10^{-7}$ & 97.927 & 6.269 & 97.927 & 6.02 \\
\hline $\mathbf{4}$ & $2.75 \times 10^{-3}$ & $1.88 \times 10^{-6}$ & 45.213 & 1.428 & 45.213 & 13.05 \\
\hline $\mathbf{5}$ & $1.4 \times 10^{-3}$ & $5.62 \times 10^{-7}$ & 11.121 & 1.021 & 11.121 & 53.05 \\
\hline $\mathbf{6}$ & $1.1 \times 10^{-3}$ & $4.09 \times 10^{-7}$ & 51.345 & 1.544 & 51.345 & 11.49 \\
\hline 7 & $1.2 \times 10^{-3}$ & $1.6 \times 10^{-7}$ & 7.858 & 11.788 & 7.858 & 75.08 \\
\hline
\end{tabular}

\subsection{Strength under Fatigue Loading}

Fatigue analysis was performed to evaluate the service life by calculating the fatigue safety factor of components 1,2 , and 3 . These components are directly experiencing the effect of the movement (fluctuated load) of the mechanism when the device is used for up and down due to the hydraulic. The type of load in this case is assumed as concentrated load. The patient is hung up by sling which attach directly at body 1 . On the other hand, components 1,2 , and 3 are also components that have the lowest static safety factor, so that these components are more critical than other components.

First, $S_{e}$ needs to be calculated. To obtain the endurance strength, it needs to determine the Marin factors and $S_{e}{ }^{\prime}$. For AISI 1080 carbon steel, the $S_{u t}$ is $780 \mathrm{MPa}$. In the calculation, the component 1 has the highest endurance limit while the component 2 has the lowest endurance limit. For the surface factor, $k_{a}$, use Equation (7) after determining factor $a$ and $b$. For the size factor, $k_{b}$, use Equation (8) based on $d_{e}$ by Equation (11). For the loading factor, $k_{c}$, use Equation (12) based on the loading. For the ideal endurance limit, use Equation (13) based on $S_{u t}$. While the rest Marin factors are assumed as 1. Below is the sample calculation for the marin factor that conducted in component 2.

- $\quad$ Surface factor, $k_{a}$

For cold drawn surface finish, $a=4.51$ and $b=-0.265$, then using Equation (7) to obtain $k_{a}$.

- $\quad$ Size factor, $k_{b}$

$$
k_{a}=4.51(635)^{-0.265}=0.8155
$$

For the rectangular section of dimension, find the equivalent diameter using Equation (11).

$$
d_{e}=0.88((50)(40))^{\frac{1}{2}}=36.1349 \mathrm{~mm}
$$

Because $2.79 \leq d_{e} \leq 51 \mathrm{~mm}$, compute the $k_{b}$ using Equation (8).

- $\quad$ Loading factor, $k_{c}$

$$
k_{b}=1.24(36.1349)^{-0.107}=0.8447
$$

According to Equation (12), $k_{c}$ for bending loading,

$$
k_{c}=1
$$

- $\quad$ For $k_{d}, k_{e}$, and $k_{f}$, assume them as 1 .

- Endurance limit, $S_{e}^{\prime}$ 
Because $S_{u t} \leq 1400 M P a$, according to Equation (13), $S_{e}^{\prime}=0.5(635)=317.5 \mathrm{MPa}$

From those calculation, $S_{e}$ can be calculated using Equation (6).

$$
S_{e}=(0.8155)(0.8447)(1)(317.5)=218.7108 \mathrm{MPa}
$$

Because in component 1 and 2 there are static stress-concentrated factor, $K_{t}$. Therefore, the fatigue-concentrated factor, $K_{f}$ can be calculated using Equation (14). $K_{f}$ in component 2 is shown below, for its value is higher than component 1 .

$$
S_{u t}=780 \mathrm{MPa}=113.129 \mathrm{kpsi} ; K_{t}=2.6 ; r=2.5 \mathrm{~mm}
$$

Calculate the modification factor, $\sqrt{a}$, by Equation (15).

$$
\begin{gathered}
\sqrt{a}=0.246-3.08\left(10^{-3}\right)(113.129)+1.51\left(10^{-5}\right)(113.129)^{2} \\
-2.67\left(10^{-8}\right)(113.129)^{3} \\
=0.0521 \sqrt{i n}=0.2626 \sqrt{m m}
\end{gathered}
$$

Thus,

$$
K_{f}=1+\frac{2.6-1}{1+\frac{0.2626}{\sqrt{2.5}}}=2.2711
$$

After the value of $\sqrt{a}$ was obtained, then for the $K_{f}$ can be calculated if the unknown variables already obtained. Then, for calculating the fatigue safety factor, we need to calculate the $\sigma_{r e v}, \sigma_{a}$, and $\sigma_{m}$.

$\sigma_{a}$ and $\sigma_{m}$ need to be calculated first using Equation (16) and Equation (17). For the $\sigma_{\max }$, use the data from maximum normal stress as loading stress that already listed in Table 3. While for $\sigma_{\min }$, it is for unloading and use 0 for this. Then calculate $\sigma_{r e v}$ using Equation (18). Below is the sample calculation in component 2 .

$$
\begin{gathered}
\sigma_{a}=\left|\frac{189.59-(0)}{2}\right|=94.795 \mathrm{MPa} \\
\sigma_{m}=\frac{0+189.59}{2}=94.795 \mathrm{MPa} \\
\sigma_{\text {rev }}=\frac{94.795}{1-\left(\frac{94.795}{780}\right)}=107.9095 \mathrm{MPa}
\end{gathered}
$$

In Table 4 shows the values of $\sigma_{a}, \sigma_{m}$, and $\sigma_{\text {rev }}$ for components 1,2 , and 3. From those values, now the fatigue safety factor can be determined by Equation (19). For the component 2 is calculated in the following. Furthermore, the summarized values of fatigue safety factor for those components are listed in Table 4. From the table, it shows that all $n_{f}>$ 1 , it means that infinite service life can be predicted for components 1,2 , and 3 . This implies the proposed design can be considered for real application and further studied for the fabrication process.

$$
n_{f}=\frac{254.4211}{(107.9095)(2.2711)}=1.0381
$$


D.C. Hardiyasanti et al. / Journal of Mechanical Design and Testing 3(2), (2021), 133-147

Table 4. Fatigue Analysis Result

\begin{tabular}{|c|c|c|c|c|c|}
\hline \multirow{2}{*}{ Components } & \multicolumn{5}{|c|}{ Values } \\
\cline { 2 - 6 } & $\begin{array}{c}\text { Fatigue } \\
\text { Concentration } \\
\text { Factor, } \boldsymbol{K}_{\boldsymbol{f}}\end{array}$ & $\begin{array}{c}\boldsymbol{\sigma}_{\boldsymbol{a}} \\
\mathbf{M P a}\end{array}$ & $\begin{array}{c}\boldsymbol{\sigma}_{\boldsymbol{m}} \\
(\mathbf{M P a})\end{array}$ & $\begin{array}{c}\boldsymbol{\sigma}_{\boldsymbol{r e v}} \\
\mathbf{M P a}\end{array}$ & $\begin{array}{c}\text { Fatigue } \\
\text { Safety } \\
\text { Factor, } \boldsymbol{n}_{\boldsymbol{f}}\end{array}$ \\
\hline $\mathbf{1}$ & 2.0203 & 80.090 & 80.090 & 88.0099 & 1.5054 \\
\hline $\mathbf{2}$ & 2.2711 & 94.795 & 94.795 & 107.9095 & 1.0381 \\
\hline $\mathbf{3}$ & - & 48.964 & 48.964 & 51.8141 & 5.1686 \\
\hline
\end{tabular}

\section{CONCLUSION}

The present work can be concluded into three points as follow:

1. The patient lifting device has been designed and analyzed in this study. The crane and hydraulic mechanism used in this device is to transfer, lift, and lower the determined maximum load of 2,000 N. From the static stress analysis, it is found that there are three critical components, yet the most critical parts are known at the fork structure (component 2) with safety factor of 3.11. Since this value is $>1$, the whole design is considered in the safety condition.

2. Moreover, the components which affected by dynamic (fatigue) loading as well as the most critical components in this case are then analyzed. The result of the fatigue analysis shows that the fork structure experiences the most critical fatigue safety factor of 1.04. Since the value $>1$, it indicates infinite service life. Therefore, the overall design of the patient lifting device is considered safe to be used without any failure.

3. In addition, the result presented in this paper can be used as reference for producing innovative tool or equipment to help the COVID-19 patient handling at the hospital or medical care station. Recommendation for further study in this device is on the ergonomic design, material selection for cost consideration, and features that can give automatic function such as for the height adjustment.

\section{REFERENCES}

Aljohani, W. A., \& Pascua, G. P., 2019, Impacts of Manual Handling Training and Lifting Devices on Risks of Back Pain among Nurses: An Integrative Literature Review, Nurse Media Journal of Nursing, 9, 2, 210-230.

Badaruddin, M., Sugiri, A., \& Wang, C. J., 2020, An experimental investigation of the mechanical strength of cold-drawn AISI 1018 steel under high-temperature steady- and transientstate conditions, Construction and Building Materials, 232, 117-193.

Budiman, B. A., Sambegoro, P. L., Rahardian, S., Ilhamsyah, R., Firmansyah, R., Juangsa, F. B., \& Aziz, M., 2020, Prediction of the remaining service lifetime of inflatable rubber dam with deep hole damage, Indonesian Journal of Science and Technology, 5, 3, 366-381.

Gholami, M., Fawad, I., Shadan, S., Rowaiee, R., Ghanem, H. A., Hassan Khamis, A., \& Ho, S. B., 2021, COVID-19 and healthcare workers: A systematic review and meta-analysis, International Journal of Infectious Diseases, 104, 335-346.

Gorkunov, E. S., Zadvorkin, S. M., Goruleva, L. S., Makarov, A. V, \& Pecherkina, N. L., 2017, Structure and mechanical properties of a high-carbon steel subjected to severe deformation, Physics of Metals and Metallography, 118, 10, 1006-1014. 
Iswanto, W. D. P. P. T., 2020, Analisis Kegagalan Poros Shipping Pump Pada Anjungan Produksi Minyak dan Gas Bumi Lepas Pantai, Journal of Mechanical Design and Testing, 2, 2 , 137-146.

Khoiriyah, N., Alfatih, S. A., Munir, M., \& Triawan, F., 2021, Component Design and Strength Analysis of Coffin Lowering Machine for COVID-19 Corpse: A Problem-Based Learning, Indonesian Journal of Multidiciplinary Research, 1, 1, 137-150.

Misnaniarti, M., Hidayat, B., Pujiyanto, P., Nadjib, M., Thabrany, H., Junadi, P., Besral, B., Purwoko, B., Trihono, T., \& Yulaswati, V., 2018, Ketersediaan Fasilitas dan Tenaga Kesehatan Dalam Mendukung Cakupan Semesta Jaminan Kesehatan Nasional, Jurnal Penelitian Dan Pengembangan Pelayanan Kesehatan, 1, 1, 6-16.

Muryanti, L., Fitria, L. N., Hanaya, G., \& Triawan, F., 2021, Foldable Bed Design Concept for COVID-19 Patient: A Machine Design Case Study, ASEAN Journal of Science and Engineering, 1, 2, 127-140.

Oktamianti, P., \& Pebrina, A., 2019, Kajian Kebutuhan Pengembangan Rumah Sakit Pemerintah Daerah Kelas B di Provinsi Sulawesi Utara, Jurnal ARSI, 5, 2, 59-71.

Oktaviandri, M., \& Paramasivam, D. K. A. V., 2020, Design and Fabrication of Customized Ais Kacang Vending Machine, Indonesian Journal of Computing, Engineering and Design (IJoCED), 2, 1, 24-31.

Pal, R., \& Yadav, U., 2021, Resurgence of COVID-19 in India: Time for introspection, Postgraduate Medical Journal, 10-11.

Pookarath, H. H., \& Parameswaran, M., 2018, Design of Equipments that helps in Patient Transferring, 1967-1969.

R. G. Budynas, J. K. Nisbett, and J. E. Shigley, 2020, Shigley's Mechanical Engineering Design Tenth Edition. New York, NY: McGrawHill Education.

Rusca Putra, K., \& Setyowati, 2019, Prevalence of burnout syndrome among nurses in general hospitals in provincial East Java: Cross-sectional study, Enfermeria Clinica, 29, 362-366.

Saptaji, K., Afiqah, S. N., \& Ramdan, R. D., 2019, A Review on Measurement Methods for Machining Induced Residual Stress, Indonesian Journal of Computing, Engineering and Design (IJoCED), 1, 2, 106-120.

Boughattas, W., El Maalel, O., Maoua, M., Bougmiza, I., Kalboussi, H., Brahem, A., Chatti, S., Mahjoub, F. and Mrizak, N., 2017, Low Back Pain among Nurses: Prevalence, and Occupational Risk Factors, Occupational Diseases and Environmental Medicine, 5, 26- 37.

Zulaikah, S., Rahmanda, W. H., \& Triawan, F., 2020, Foldable Front Child-Seat Design for Scooter Motorcycle: Strength Analysis Under Static and Dynamic Loading, Internatioal Journal of Sustainable Transportation Techology, 3, 2, 37-44. 